\title{
Genomic selection of milk fatty acid composition in Sarda dairy sheep: Effect of different phenotypes and relationship matrices on heritability and breeding value accuracy
}

\author{
A. Cesarani, G. Gaspa, ${ }^{*}$ F. Correddu, M. Cellesi, C. Dimauro, and N. P. P. Macciotta \\ Dipartimento di Agraria, University of Sassari, Viale Italia 39, 07100 Sassari, Italy
}

\begin{abstract}
Fatty acid (FA) composition is one of the most important aspects of milk nutritional quality. However, the inclusion of this trait as a breeding goal for dairy species is hampered by the logistics and high costs of phenotype recording. Fourier-transform infrared spectroscopy (FTIR) is a valid and cheap alternative to laboratory gas chromatography (GC) for predicting milk FA composition. Moreover, as for other novel phenotypes, the efficiency of selection for these traits can be enhanced by using genomic data. The objective of this research was to compare traditional versus genomic selection approaches for estimating genetic parameters and breeding values of milk fatty acid composition in dairy sheep using either GC-measured or FTIR-predicted FA as phenotypes. Milk FA profiles were available for a total of 923 Sarda breed ewes. The youngest 100 had their own phenotype masked to mimic selection candidates. Pedigree relationship information and genotypes were available for 923 and 769 ewes, respectively. Three statistical approaches were used: the classical-pedigree-based BLUP, the genomic BLUP that considers the genomic relationship matrix $\mathbf{G}$, and the single-step genomic BLUP (ssGBLUP) where pedigree and genomic relationship matrices are blended into a single $\mathbf{H}$ matrix. Heritability estimates using pedigree were lower than ssGBLUP, and very similar between GC and FTIR regarding the statistical approach used. For some FA, mostly associated with animal diet (i.e., C18:2n-6, C18:3n-3), random effect of combination of flock and test date explained a relevant quota of total variance, reducing the heritability estimates accordingly. Genomic approaches (genomic BLUP and ssGBLUP) outperformed the traditional pedigree method both for GC and FTIR FA. Prediction accuracies in the older cohort were larger than the
\end{abstract}

Received July 5, 2018.

Accepted December 13, 2018.

*Corresponding author: gigaspa@uniss.it young cohort. Genomic prediction accuracies (obtained using either $\mathbf{G}$ or $\mathbf{H}$ relationship matrix) in the young cohort of animals, where their own phenotypes were masked, were similar for GC and FTIR. Multiple-trait analysis slightly affected genomic breeding value accuracies. These results suggest that FTIR-predicted milk FA composition could represent a valid option for inclusion in breeding programs.

Key words: mid-infrared spectra, restricted maximum likelihood, Fourier-transform infrared spectroscopy, genomic selection

\section{INTRODUCTION}

Dairy sheep breeding programs have been historically aimed at improving total milk yield per lactation (Carta et al., 2009). Although sheep milk is almost totally destined to cheese making (Pulina et al., 2018), selection for milk composition is carried out only in few breeds (Macciotta et al., 2005; Astruc et al., 2008). This is mostly because of the high recording costs compared with the income per ewe (Carta et al., 2009; Rupp et al., 2016). On the other hand, the increasing consumer interest on dairy product nutritional quality pushes toward the inclusion of fine milk composition traits among breeding goals of dairy species. An example is represented by CLA, known for its relationships with human health (Banni et al., 2003; Bhattacharya et al., 2006; Mele et al., 2011). Ruminant dairy products are among the most important sources of CLA in human diets (Nudda et al., 2014). Although animal feeding is considered the most important factor affecting milk fatty acid (FA) composition (Cabiddu et al., 2005; Sánchez et al., 2010), genetic variation for these traits has been reported in cattle (Stoop et al., 2008; Pegolo et al., 2016) and sheep (Sánchez et al., 2010; Correddu et al., 2018), suggesting the possibility for a genetic improvement.

The inclusion of milk FA composition as breeding goal for dairy sheep programs is constrained by logistics and costs of phenotype recording. The standard method for measuring milk FA composition is GC analysis, which 
is expensive and time consuming. A population-scale recording of milk FA appears therefore rather unfeasible for species where also the routine phenotyping of milk components is economically unbearable. A valid alternative to GC is represented by Fourier-transform infrared (FTIR) spectroscopy. This technique, implemented in milk laboratory equipment currently used for routine milk composition analysis, produces a spectrum of approximately 1,000 variables that could be used for large-scale prediction of novel phenotypes, including FA (e.g., Cecchinato et al., 2009; De Marchi et al. 2011; McParland et al., 2011; Dehareng et al., 2012; Fleming, 2016). Good prediction accuracies of milk FA based on FTIR spectrum have been reported for dairy cattle (Arnould and Soyeurt, 2009; De Marchi et al., 2011). Similar results, even though with a certain degree of variability and in a limited number of studies, have been reported for dairy sheep (Ferrand-Calmels et al., 2014; Caredda et al., 2016; Correddu et al., 2018). Fatty acid predicted by FTIR exhibited genetic variation both in dairy cattle (e.g., Soyeurt et al., 2007; Bastin et al., 2013; Narayana et al., 2017) and sheep (Sánchez et al., 2010; Boichard et al., 2014). Moreover, genetic correlations ranging from 60 to $99 \%$ between FTIR-predicted and GC-measured milk FA have been reported both in cattle (Bonfatti et al., 2017) and sheep (Correddu et al., 2018).

Dairy sheep breeding programs are based on the classical quantitative genetic approach, with a pyramidal organization of the population, large-scale registration of phenotypes and pedigree, and genetic evaluations of AI rams based on progeny testing (Carta et al., 2009; Baloche et al., 2014). The availability of a high-throughput SNP panel for sheep has opened the perspective of genomic selection (GS) also for this species. Studies have been carried out on dairy (Duchemin et al., 2012; Baloche et al., 2014), meat, and wool sheep (Daetwyler et al., 2012). An improvement of genomic breeding value (GEBV) accuracies over the traditional pedigree index has generally been observed, even though to a lesser extent compared with dairy cattle (Legarra et al., 2014).

Genomic studies on milk FA in cattle have focused mostly on the study of their genetic determinism (Stoop et al., 2009; Bouwman et al., 2011; Buitenhuis et al., 2014). In dairy sheep, the molecular basis of FA has been investigated by candidate gene (Crisà et al., 2010; Moioli et al., 2012), and QTL detection (Carta et al., 2008) approaches. Genomic selection studies for FA compositions are limited to beef cattle (Uemoto et al., 2011; Chen et al., 2015; Zhu et al., 2017) and meat sheep (Rovadoscki et al., 2018). One of the main advantages of GS over traditional selection is that, once a reference population with both phenotypic and genotypic records has been settled, breeding values of animals without their own phenotypes can be predicted with a reasonable accuracy (Meuwissen et al., 2001; Hayes et al., 2009). Therefore, GS seems to be an appealing option for novel traits that are difficult to measure routinely as milk FA composition (Boichard and Brochard, 2012; Daetwyler et al., 2012).

The aim of the present work is to explore the feasibility of breeding for milk FA composition in a dairy sheep breed by combining the use of FTIR-predicted phenotypes and GS technology. For this purpose, breeding value prediction was carried out with a pedigree-based and 2 genomic models, using either FTIR-predicted and GC-measured FA as phenotypes. Moreover, the effects of the different phenotypes used and of the estimation methods on heritability $\left(\mathbf{h}^{2}\right)$ were tested.

\section{MATERIALS AND METHODS}

\section{Data}

A sample of 923 Sarda breed dairy ewes farmed in 47 flocks located in the island of Sardinia (Italy) were considered. Milk samples, one per animal, were collected from February to June 2015 (Table 1). In this study 13 individual FA (C4:0, C6:0, C8:0, C10:0, C12:0, C14:0, C16:0, C18:0, C18:1 trans-11, C18:1 cis-9, C18:2n-6, C18:3n-3, and CLA cis-9,trans-11), 5 groups of FA, and a ratio between groups of FA were analyzed. Groups of FA were calculated as follows (Appendix Table A1): SFA, sum of individual SFA; MUFA, sum of individual MUFA; PUFA, sum of individual PUFA; TFAnoVA, sum of individual trans FA with the exclusion of C18:1 trans-11 (vaccenic acid); de novo, sum of individual FA that are de novo synthesized in the mammary gland; and PUFA n-6:PUFA n-3, ratio between the sum of individual PUFA n-6 and the sum of all individual PUFA n-3. Milk FA (g of FA/100 g of total FA) composition was both measured by gas chromatography (FA_GC) and predicted by partial least square regression using the FTIR spectra (FA_FTIR) generated by milk analysis performed with Milkoscan FT6000 instrument (Foss, Hillerød, Denmark). The partial least square regression was carried out by extracting 18 latent factors. Prediction accuracies were tested by using a calibration data set of 700 ewes and a validation data set of 223 ewes, respectively. One hundred replicates randomly assigning animals to the 2 data sets were performed. Details for GC analysis are reported in the work of Correddu et al. (2018).

Genotypes obtained with the Infinium Ovine SNP50 v1 BeadChip (Illumina Inc., San Diego, California) were available for 769 ewes out of 923. Quality control of SNP genotypes was carried out with PLINK software 
(Purcell et al., 2007). All genotyped ewes had a call rate greater than 0.95 . A SNP was discharged if the call rate was lower than 0.975 (867 markers removed), the minor allele frequency was lower than $0.01(1,309$ markers removed), it deviated significantly from the Hardy-Weinberg equilibrium $(P<0.01,1,264$ markers removed), or it did not map to the OAR_v3.1 assembly (6,182 markers removed; International Sheep Genomics Consortium, 2010; Nicolazzi et al., 2015). After quality control, all genotyped ewes and 44,619 SNP across 27 chromosomes were retained for the analysis. A pedigree with 633,317 animals was also available.

\section{Variance Component Estimation}

Variance components for FA_GC and FA_FTIR traits were estimated by REML using 3 mixed linear models that differed in the relationship matrix used.

The following mixed linear model was implemented:

$$
\mathbf{y}=\mathbf{X b}+\mathbf{Q f}+\mathbf{Z a}+\mathbf{e},
$$

where $\mathbf{y}$ is the vector of investigated $\mathrm{FA} ; \mathbf{X}$ is the incidence matrix linking records to fixed effects and $\mathbf{b}$ is the related vector; $\mathbf{Q}$ is the incidence matrix for random flock test-date combination (FTD) effect and $\mathbf{f}$ is the related vector (71 classes) distributed as $N\left(\mathbf{0}, \mathbf{I} \sigma_{\mathrm{FTD}}^{2}\right)$, where $\mathbf{I}$ is an identity matrix and $\sigma_{\mathrm{FTD}}^{2}$ is the associated variance component; $\mathbf{Z}$ is the incidence matrix for random genetic effects, relating records to animals, and a

Table 1. Flock statistics and distribution of records for fixed effects considered in the analysis

\begin{tabular}{lcc}
\hline Observations & no. & $\%$ \\
\hline Flocks & 47 & \\
Ewes/flock $( \pm$ SD $)$ & $19.6 \pm 7.2$ & \\
Parity & 186 & 20 \\
1 & 123 & 13 \\
2 & 151 & 16 \\
3 & 164 & 18 \\
4 & 116 & 13 \\
5 & 95 & 10 \\
6 & 68 & 7 \\
7 & 20 & 2 \\
$>7$ & & 15 \\
Lambing month & 142 & 14 \\
Jan & 130 & 41 \\
Feb-Mar & 377 & 30 \\
Oct-Nov & 274 & \\
Dec & & 15 \\
Altitude & 135 & 52 \\
Mountain $(>500 \mathrm{~m})$ & 480 & 33 \\
Hill $(200-500 \mathrm{~m})$ & 308 & 100 \\
Plain $(<200 \mathrm{~m})$ & 923 & \\
Total & &
\end{tabular}

is the vector of breeding values (a distributed according to the relationship matrix used); and $\mathbf{e}$ is the vector of random residuals distributed as $N\left(\mathbf{0}, \mathbf{I} \sigma_{e}^{2}\right)$, where $\sigma_{e}^{2}$ is the residual variance. The fixed effects (Table 1 ) considered in the model were parity ( 8 classes), DIM (5 classes), lambing month (4 classes), and altitude of farm (3 classes).

The additive genetic effect was modeled using 3 genetic (co)variance structures. In the first model (ABLUP), the pedigree relationship matrix (A) was used and the animal effect was distributed as $N\left(\mathbf{0}, \mathbf{A} \sigma_{a}^{2}\right)$, where $\sigma_{a}^{2}$ is the additive genetic variance. The other 2 genomic models used the genomic relationship matrix (G; GBLUP) or a blend of genomic and pedigree relationship matrices $(\mathbf{H})$ in a single-step framework (ssGBLUP) with a distributed as $N\left(\mathbf{0}, \mathbf{G} \sigma_{a}^{2}\right)$ and $N\left(\mathbf{0}, \mathbf{H} \sigma_{a}^{2}\right)$, respectively. From whole pedigree, 3 generations were traced back from the phenotyped animals; the composition and number of animals of the different relationship matrices are reported in Table 2. The $\mathbf{G}$ and $\mathbf{H}$ matrices were computed according to VanRaden (2008) and Aguilar et al. (2010), respectively. The AIREML algorithm implemented in blupf90 family software was used for estimating variance components (Misztal et al., 2015). Heritability and intra-flock heritability $\left(\mathrm{h}_{\mathrm{IF}}^{2}\right)$ were computed respectively as

$$
\begin{gathered}
\mathrm{h}^{2}=\sigma_{a}^{2} /\left(\sigma_{a}^{2}+\sigma_{\mathrm{FTD}}^{2}+\sigma_{e}^{2}\right)^{\prime} \\
\mathrm{h}_{\mathrm{IF}}^{2}=\sigma_{a}^{2} /\left(\sigma_{a}^{2}+\sigma_{e}^{2}\right) ;
\end{gathered}
$$

moreover, variance explained by FTD $\left(\mathrm{r}_{\mathrm{FTD}}^{2}\right)$ was computed as

$$
\mathrm{r}_{\mathrm{FTD}}^{2}=\sigma_{\mathrm{FTD}}^{2} /\left(\sigma_{a}^{2}+\sigma_{\mathrm{FTD}}^{2}+\sigma_{e}^{2}\right)
$$

\section{Breeding Value Predictions}

Breeding values were predicted using model [1] with the traditional (ABLUP) and the 2 GS (GBLUP and ssGBLUP) approaches, respectively. From the 769 animals with genotypes and own phenotypes, records of the 100 youngest ewes (born after November 2012) were masked to mimic the condition of candidate animals.

Accuracy of breeding values animals were estimated as 


$$
\text { accuracy }=\sqrt{1-\mathrm{SEP}^{2} / \sigma_{a}^{2}},
$$

where SEP is the standard error of prediction, derived from the diagonal element of the left-hand side inverse of the mixed model equations. To ensure a fair comparison among accuracies obtained in the 3 different methods, the same variance components (the ones estimated with ABLUP) were used in the 3 approaches for breeding value predictions and computation of accuracy.

Moreover, to reduce GEBV bias in the ssGBLUP, a weighing factor omega $(\omega)$ equal to 0.95 was applied in construction of the inverse of the $\mathbf{H}$ matrix (Tsuruta et al., 2013):

$$
\mathbf{H}^{-1}=\mathbf{A}^{-1}+\left[\begin{array}{ccc}
0 & 0 \\
0 & \mathbf{G}^{-1}-\omega \mathbf{A}_{22}^{-1}
\end{array}\right],
$$

where $\mathbf{A}_{22}$ is the pedigree-based relationship matrix for genotyped animals.

As FA are genetically correlated traits (Carta et al., 2008; Sánchez et al., 2010), GEBV accuracy of individual FA may be modified when a multiple-trait instead of a single-trait approach is used. However, considering the large number of FA analyzed in the present study, the effect of genetic correlations among FA on GEBV accuracy was investigated by a series of bivariate analyses using the ssGBLUP approach. Thus, for each single FA, 2 accuracies were available: one obtained with the univariate approach and another obtained as the mean accuracy of the 17 bivariate analyses involving that specific FA.

\section{RESULTS}

Basic statistics (Table 3) of the milk FA_GC and FA_FTIR, and coefficients of determination of the regression between FA_GC and FA_FTIR $\left(\mathrm{R}_{\text {GC-FTIR }}^{2}\right)$ essentially confirm previous reports on dairy sheep (Fer-
rand-Calmels et al., 2014; Caredda et al., 2016; Correddu et al., 2018).

\section{Genetic Parameters of Milk FA Profile}

Heritability estimates showed relevant variations across different FA, phenotyping methods (GC vs. FTIR), and models (Table 4). Overall, low to moderate values were obtained, apart from $\mathrm{C} 4: 0$ and $\mathrm{C} 16: 0$. The largest $\mathrm{h}^{2}$ were observed for the C4:0 FA_FTIR in the GBLUP (0.56), and for the C16:0 FA_GC in the ABLUP (0.46; Table 4), respectively. A similar pattern was detected for intra-flock heritabilities (Table 5), which exhibited larger values compared with $\mathrm{h}^{2}$, especially for FA characterized by a larger flock-test date variance (Table 6; e.g., C18:0, C18:1 trans-11, C18:1 cis-9, C18: 2n-6, C18:3n-3, CLA cis-9,trans-11, and n-6:n-3). The lowest estimates (almost zero) were obtained for SFA and MUFA in the ABLUP, and for C18:2n-6 in all the 3 prediction models for FA_FTIR.

The considered phenotype, FA_GC or FA_FTIR, affected the $\mathrm{h}^{2}$ results, even though no defined patterns were observed. For example, FA_GC estimates were markedly larger than FA_FTIR for C16:0 in all models (Table 4). On the contrary, FA_GC estimates were smaller for C4:0, especially for the 2 genomic models. It should be also noticed that the $\mathrm{h}^{2}$ estimated with $\mathrm{AB}$ LUP were close to zero for SFA and MUFA using FA_ FTIR phenotypes. To highlight recurrent pattern in the additive genetic component, $\sigma_{a}^{2}$ for FA_GC was regressed onto $\sigma_{a}^{2}$ for FA_FTIR (Figure 1) for the 3 models used. Additive genetic variances estimated using FA_GC and FA_FTIR were from moderately to strongly correlated depending on the (co)variance matrix used.

The $\mathrm{h}^{2}$ and $\mathrm{h}_{\mathrm{IF}}^{2}$ estimated with ABLUP were generally lower than those obtained with the 2 genomic approaches, both for FA_GC and FA_FTIR (Tables 4 and 5). Exceptions were the C16:0 and C18:0, which showed an opposite behavior. In particular, the largest

Table 2. Type of relationship matrices used and number of animals for the 3 (co)variance structures

\begin{tabular}{lccc}
\hline & \multicolumn{3}{c}{ Matrix $^{1}$} \\
\cline { 2 - 4 } Animals, no. & $\mathbf{A}$ & $\mathbf{G}$ & $\mathbf{H}$ \\
\hline With genotypes and own phenotypes & 769 & 769 & 769 \\
Without genotypes and with own phenotypes & 154 & - & 154 \\
Other relatives without phenotype & 3,924 & - & 3,924 \\
Total & 4,847 & 769 & 4,847 \\
\hline
\end{tabular}

${ }^{1} \mathbf{A}=$ pedigree relationship matrix; $\mathbf{G}=$ genomic relationship matrix; $\mathbf{H}=$ pedigree and genomic relationship matrices are blended into a single matrix. 
Table 3. Descriptive statistics of fatty acids measured using gas chromatography (FA_GC) or predicted using Fourier-transform infrared spectrum (FA_FTIR) and coefficients of determination $\left(\mathrm{R}_{\mathrm{CG}-\mathrm{FTIR}}^{2}\right)$

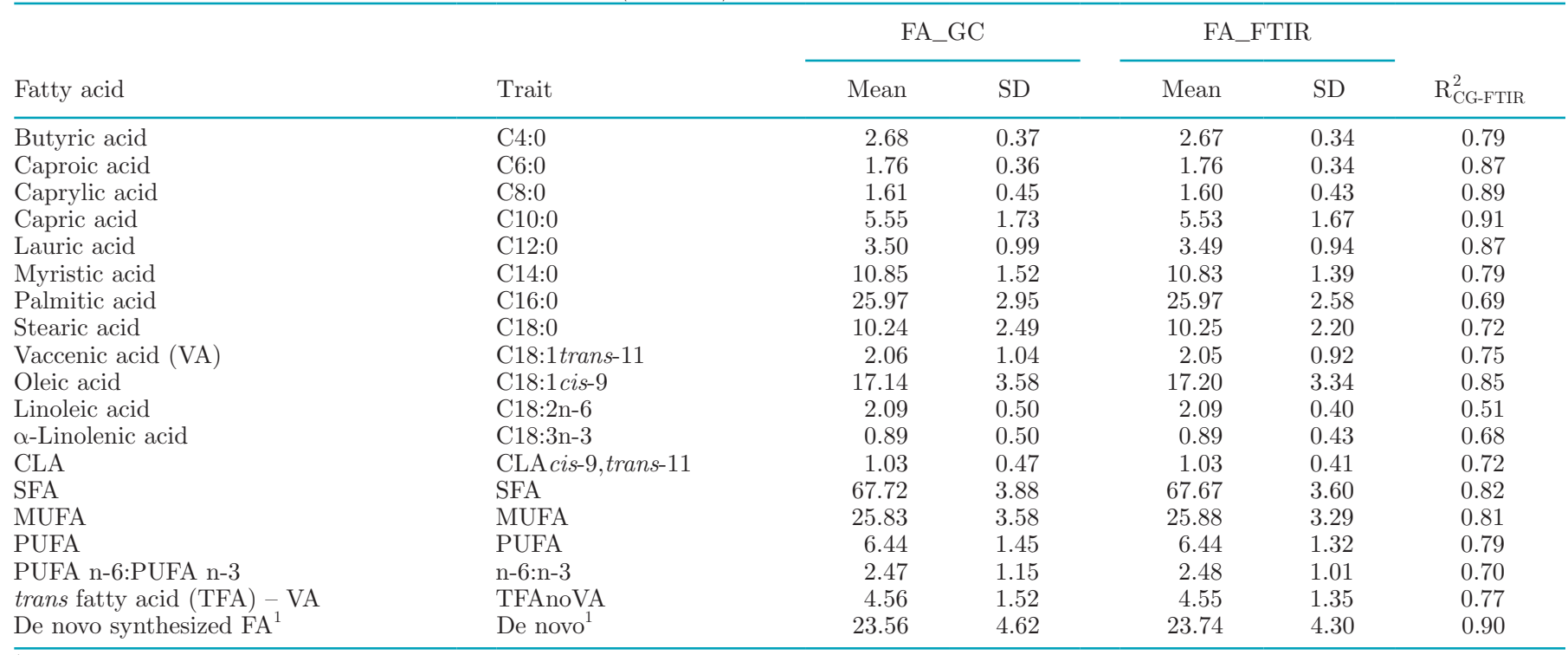

${ }^{1}$ De novo $=\mathrm{C} 6: 0, \mathrm{C} 8: 0, \mathrm{C} 10: 0, \mathrm{C} 11: 0, \mathrm{C} 12: 0$, iso-C13:0, and C14:0 that are de novo synthesized in the mammary gland.

differences were found for $\mathrm{C} 4: 0$ and $\mathrm{C} 16: 0$ as individual FA, and for SFA and MUFA as groups, respectively. The GBLUP and ssGBLUP estimates were very similar
(Tables 4 and 5). Differences among $\mathrm{h}^{2}$ estimates were mainly due to changes in the additive genetic components as shown in Appendix Table A2. In particular, for

Table 4. Heritability for milk fatty acid composition measured by gas chromatography (FA_GC) or predicted by Fourier-transform infrared spectra (FA_FTIR) using the pedigree relationship matrix (ABLUP), genomic relationship matrix (GBLUP), blended genomic-pedigree matrix (ssGBLUP), respectively (SE of heritability reported in parentheses)

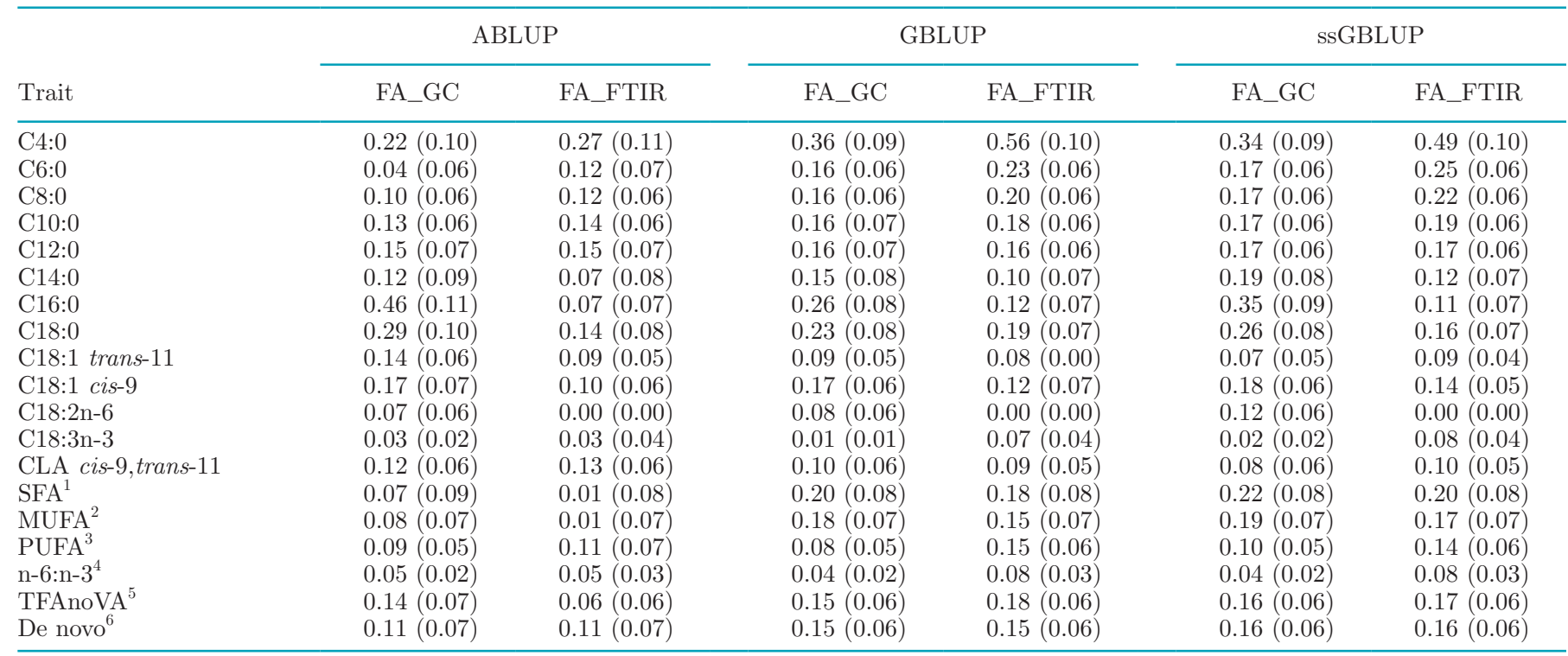

\footnotetext{
${ }^{1}$ Sum of the individual SFA.

${ }^{2}$ Sum of the individual MUFA.

${ }^{3}$ Sum of the individual PUFA; odd- and branched-chain fatty acids.

${ }^{4}$ Ratio between the sum of individual PUFA n-6 fatty acids and the sum of individual PUFA n-3 fatty acids.

${ }^{5}$ trans fatty acid (TFA) without vaccenic acid (VA).

${ }^{6}$ Sum of C6:0, C8:0, C10:0, C11:0, C12:0, iso-C13:0, and C14:0 that are de novo synthesized in the mammary gland.
} 
Table 5. Intra-flock heritability $\left(\mathrm{h}_{\mathrm{IF}}^{2}\right)$ for milk fatty acid composition measured by gas chromatography (FA_GC) or predicted by Fouriertransform infrared spectra (FA_FTIR) using pedigree relationship matrix (ABLUP), genomic relationship matrix (GBLUP), blended genomicpedigree matrix (ssGBLUP), respectively ( $\mathrm{SE}$ of $\mathrm{h}_{\mathrm{IF}}^{2}$ reported in parentheses)

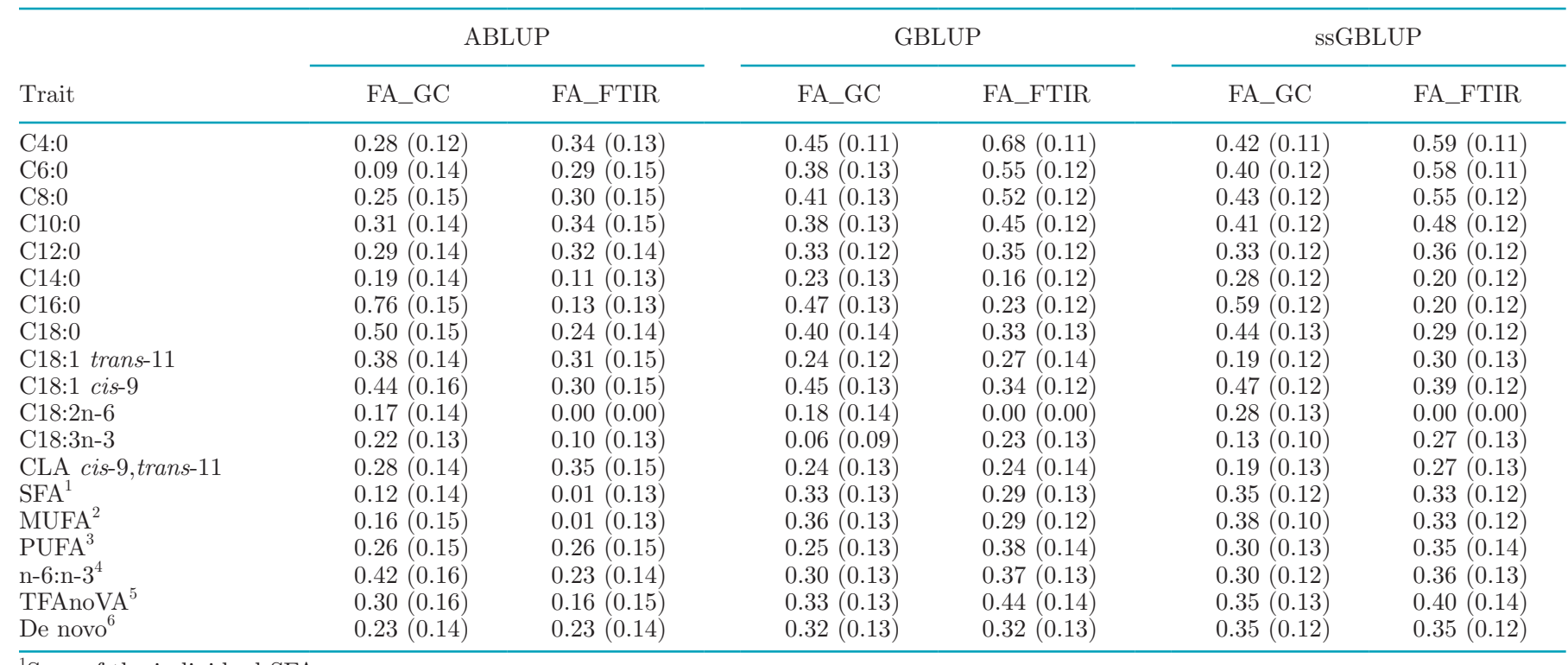

${ }^{1}$ Sum of the individual SFA.

${ }^{2}$ Sum of the individual MUFA.

${ }^{3}$ Sum of the individual PUFA; odd- and branched-chain fatty acids.

${ }^{4}$ Ratio between the sum of individual PUFA n-6 fatty acids and the sum of individual PUFA n-3 fatty acids.

${ }^{5}$ trans fatty acid (TFA) without vaccenic acid (VA).

${ }^{6}$ Sum of C6:0, C8:0, C10:0, C11:0, C12:0, iso-C13:0, and C14:0 that are de novo synthesized in the mammary gland.

most of the FA analyzed no differences in $\sigma_{a}^{2}$ were observed with genomic methods. In our study, largest values of $\mathrm{R}^{2}$ of the regression between $\sigma_{a}^{2} \mathrm{FA} \_\mathrm{GC}$ and $\sigma_{a}^{2}$ FA_FTIR were observed using genomic models (0.84 and 0.91 ) in comparison to the traditional pedigree models (0.45, Figure 1). Finally, $\sigma_{a}^{2}$ estimates of C16:0, C18:0, C18:1 cis-9, SFA, and MUFA were always higher for FA_GC than FA_FTIR.

The FTD contribution to total phenotypic variance was moderate to large. It was on average $>0.5$ across all different prediction models and phenotypes (Table 6), ranging from 0.17 to 0.88 . The variance components for FTD were almost the same in the 3 different models, whereas differences (up to 15\%) were highlighted between FA_GC and FA_FTIR (e.g., C4:0, C14:0, C18:1 trans-11, C18:2n-6, C18:3n-3, CLA, PUFA, n-3:n-6, and TFAnoVA).

\section{Accuracy of EBV and GEBV Predictions}

Accuracies of breeding values were low to moderate, ranging from 0.05 to 0.84 , and from 0.02 to 0.45 in the oldest and youngest cohort, respectively (Table 7). The palmitic acid (C16:0) showed the largest accuracy for FA_GC across the different prediction models, both for oldest (0.84) and youngest animals (0.45). The largest GEBV accuracy for FA_FTIR was observed for the butyric acid (C4:0). The linoleic acid (C18:2n-6) showed the lowest accuracy in most of the scenarios considered. Accuracies of FA groups reflected their composition, with SFA showing the lowest and PUFA and TFAnoVA the highest accuracies, respectively.

The cohort of animals with own phenotypes exhibited larger prediction accuracies compared with young animals without phenotype (overall average difference +0.24 ) in all scenarios (Table 7$)$. The largest difference $(+0.30)$ was observed for the stearic acid (C18:0), and the smallest for the SFA group $(+0.09)$.

Differences were also observed between the phenotype (FA_GC vs. FA_FTIR) for all 3 models and for the 2 cohorts of animals (Table 7), even though without a defined pattern. The major differences between FA_GC and FA_FTIR were observed in the older cohort (from -0.23 up to 0.48 for $\mathrm{C} 6: 0$ and $\mathrm{C} 16: 0$, respectively). Accuracies differed mainly in the ABLUP approach for both young and older cohorts. The difference between FA_GC and FA_FTIR tended to reduce in genomic methods applied to young animals (Table 7). Regardless of the statistical model used, the largest difference between FA_GC and FA_FTIR was observed for the 
Table 6. Proportion of phenotypic variance ${ }^{1}$ explained by flock test date $\left(\mathrm{r}_{\mathrm{FTD}}^{2}\right)$ estimated in the 3 approaches $^{2}$

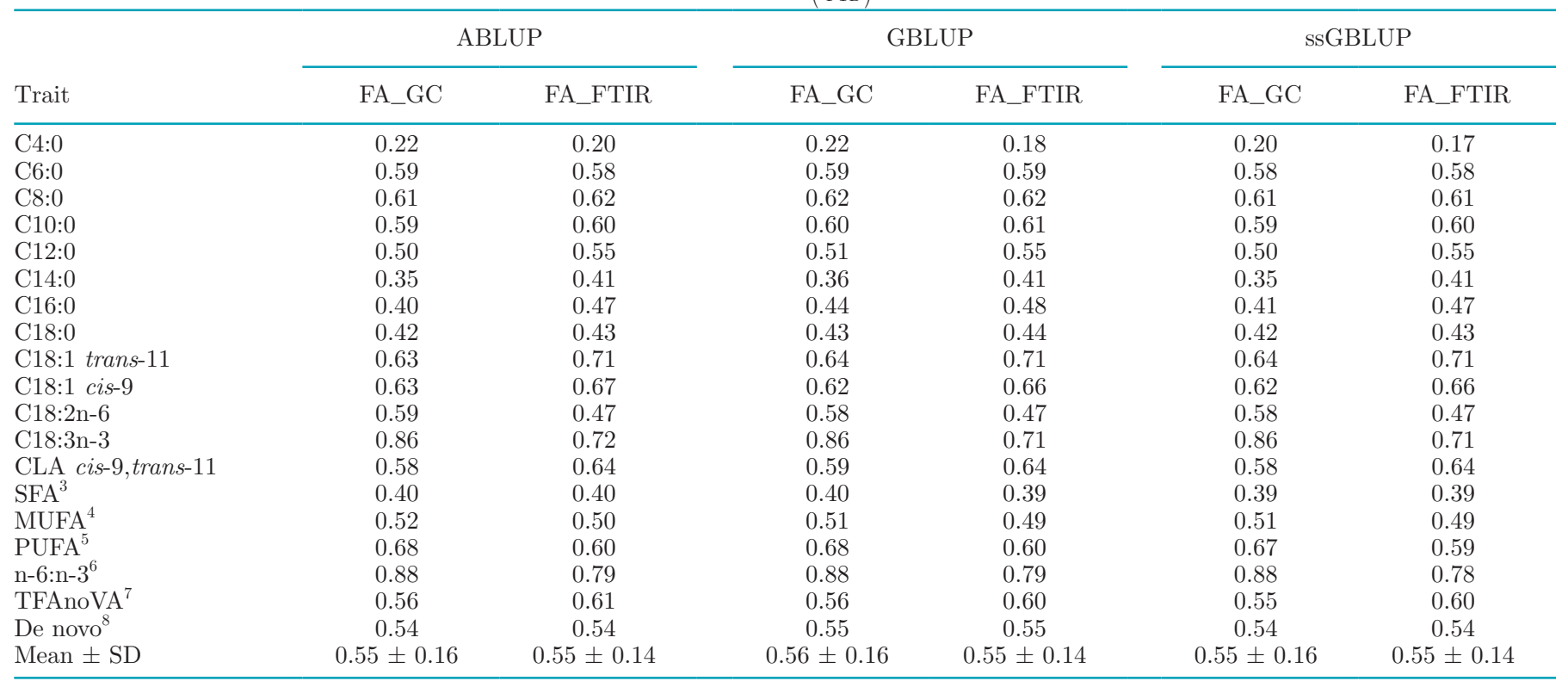

${ }^{1}$ SE between 0.02 and 0.06 for FA_GC and ranging from 0.04 to 0.04 for FA_FTIR.

${ }^{2} \mathrm{ABLUP}=$ pedigree relationship matrix; GBLUP = genomic relationship matrix; ssGBLUP = single-step genomic BLUP; FA_GC = prediction for milk fatty acids obtained with gas chromatography; FA_FTIR = milk fatty acids predicted by Fourier-transform infrared spectra.

${ }^{3}$ Sum of the individual SFA.

${ }^{4}$ Sum of the individual MUFA.

${ }^{5}$ Sum of the individual PUFA; odd- and branched-chain fatty acids.

${ }^{6}$ Ratio between the sum of individual PUFA n-6 fatty acids and the sum of individual PUFA n-3 fatty acids.

${ }^{7}$ trans fatty acid (TFA) without vaccenic acid (VA).

${ }^{8}$ Sum of C6:0, C8:0, C10:0, C11:0, C12:0, iso-C13:0, and C14:0 that are de novo synthesized in the mammary gland.

C16:0 (on average difference of 0.45 ad 0.18 for old and young animals, respectively). Relevant differences (at least $>15 \%$ ) between FA_CG and FA_FTIR were observed also for C18:0, C18:2n-6, SFA, and MUFA both in older and younger animals.

As far as the 3 models are concerned, genomic prediction accuracies were constantly higher than in ABLUP (Table 7). In particular, differences between ABLUP and genomic methods were larger in young animals. In this cohort, positive changes up to $+0.12(+0.17)$ and $+0.10(+0.21)$ were observed in the comparison GBLUP-ABLUP (ssGBLUP-ABLUP) for FA_GC and FA_FTIR, respectively. Among the 2 genomic approaches, the ssGBLUP accuracies were always larger than GBLUP ones both in young and old animal cohorts.

Bivariate GEBV accuracies for the young animals were generally of the same magnitude of those obtained using the univariate approach (Table 8). Differences were exhibited by some FA_FTIR: in particular the GEBV accuracy for linoleic acid, SFA, and MUFA showed an increase $(>0.03)$ moving from univariate to multivariate approach.

\section{DISCUSSION}

Fatty acid composition is a key feature in defining sheep milk nutritional quality. Its genetic improvement is an appealing option for enhancing market value of dairy sheep products. However, breeding for milk FA composition in sheep is hampered by difficulties in phenotyping and in implementing appropriate selection strategies. Use of equations for predicting FA from milk FTIR spectra is widely recognized as a cost-effective solution for obtaining FA profiles in milk of different ruminant species (Ferrand-Calmels et al., 2014). At the same time, early experiences of GS on meat, wool (Daetwyler et al., 2012), and dairy sheep (e.g., Duchemin et al., 2012; Legarra et al., 2014; Baloche et al., 2014) have reported an increase of breeding value accuracy and selection response compared with the traditional pedigree-based method.

Results of the present study, although referring to a sample of limited size, showed an effect of both investigated phenotypes (i.e., FA_GC or FA_FTIR) and of the information used to structure the genetic covariance among animals (pedigree, genomic, or both) on 

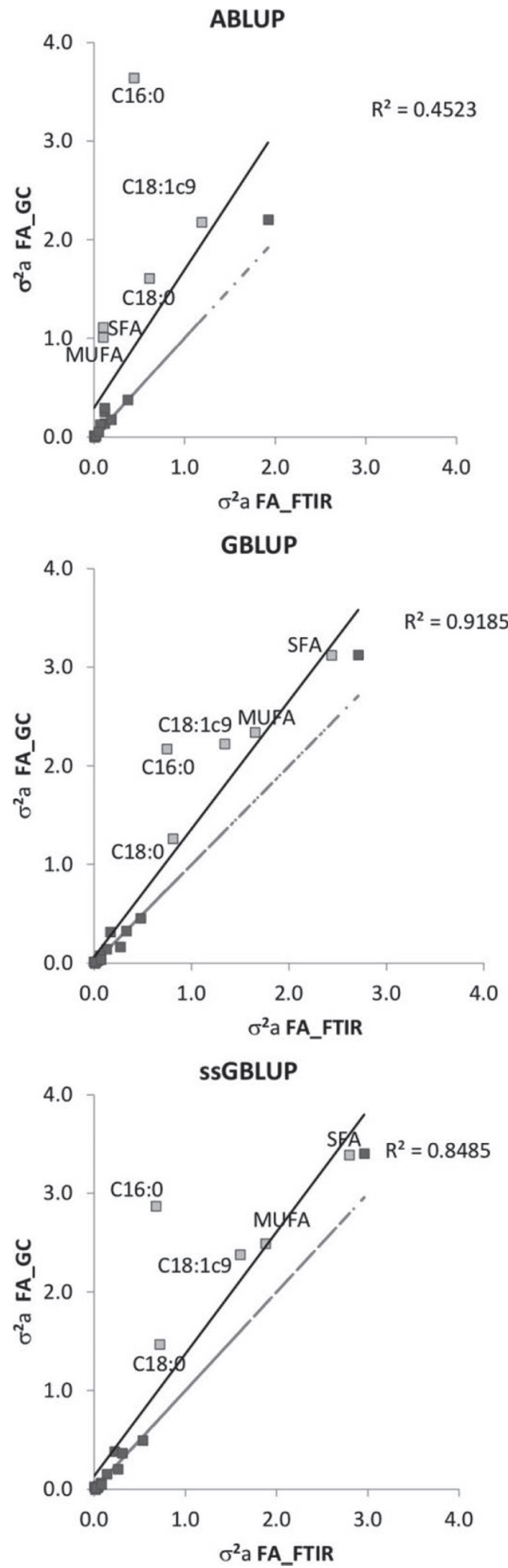

Figure 1. Regressions of additive genetic variance estimated using fatty acids measured through gas chromatography (FA_GC) and fatty acids predicted by Fourier-transform infrared spectra (FA_FTIR) within each investigated method: pedigree relationship matrix (ABLUP), genomic relationship matrix (GBLUP), and blended genomic-pedigree matrix (ssGBLUP). Dashed line represents the equivalent line $(\mathrm{y}=\mathrm{x}) \cdot \sigma_{a}^{2}=$ additive genetic variance. $\mathrm{c}=$ cis. genetic parameter estimates and breeding value prediction accuracies.

\section{Genetic Parameters of Milk FA Profile}

Heritability estimates based on pedigree models were consistent with a previous work carried out on a similar data set (Correddu et al., 2018), whereas genomicbased $\mathrm{h}^{2}$ were higher and lower than pedigree based on SFA $(<\mathrm{C} 14)$ and UFA, respectively. A large variation among different FA was observed, regardless of the considered approach or the phenotype used, in agreement with previous studies (Sánchez et al., 2010; Boichard et al., 2014). Differences among FA are mainly related to their metabolic pathway. Some FA are synthesized de novo in the mammary gland, some are mostly related to the animal diet, and others come from body reserve mobilization. Thus, larger $\mathrm{h}^{2}$ is expected for FA whose milk concentration is under enzymatic control (i.e., de novo FA) compared with FA that are related to the animal diet (Arnould and Soyeurt, 2009). The higher value of $h^{2}$ observed for de novo FA compared with those coming from diet or body fat reserves (e.g., C18 FA) seemed to confirm the stronger genetic regulation for the former group of FA (e.g., Bastin et al., 2011; Narayana et al., 2017). Moreover, the lowest $\mathrm{h}^{2}$ values were highlighted for C18:2n-6 and C18:3n-3 (Tables 4 and 5), regardless of the model used. It is well known that these 2 FA are strongly dependent on their concentration in animals' diets (e.g., Fleming, 2016; Pegolo et al., 2017).

Differences between $\mathrm{h}^{2}$ estimated using FA_GC and FA_FTIR were in most of cases low to moderate. The FA_FTIR produced larger $\mathrm{h}^{2}$ estimates for short-chain FA (Figures 1), whereas an opposite trend can be observed for medium- and long-chain FA. A similar pattern was also observed in cattle using GC (Stoop et al., 2008; Duchemin et al., 2013). The largest differences were found for FA (e.g., C16:0 and C4:0) that exhibited lowest FTIR prediction accuracies. In dairy cattle, larger $\mathrm{h}^{2}$ for FA_GC compared with FA_FTIR have been reported (Rutten et al., 2010; Bonfatti et al., 2017). In particular, Bonfatti et al. (2017) pointed out that the differences were due to a reduction of the $\sigma_{a}^{2}$ in FA_FTIR $(-0.52 \%)$ compared with FA_GC. In the present work, the use of FA_FTIR phenotypes resulted in most cases (short-chain FA) in smaller estimates for all 3 variance components (Appendix Table A2).

Apart from the values obtained for palmitic and stearic acids, pedigree-based $h^{2}$ were in most of cases lower than those obtained using genomic information. In particular, most FA showed an increase of $\sigma_{a}^{2}$ and a reduction of $\sigma_{e}^{2}$ (especially for FA_FTIR) when moving from traditional pedigree to genomic methods, respec- 
GENOMIC SELECTION FOR SHEEP MILK FATTY ACIDS

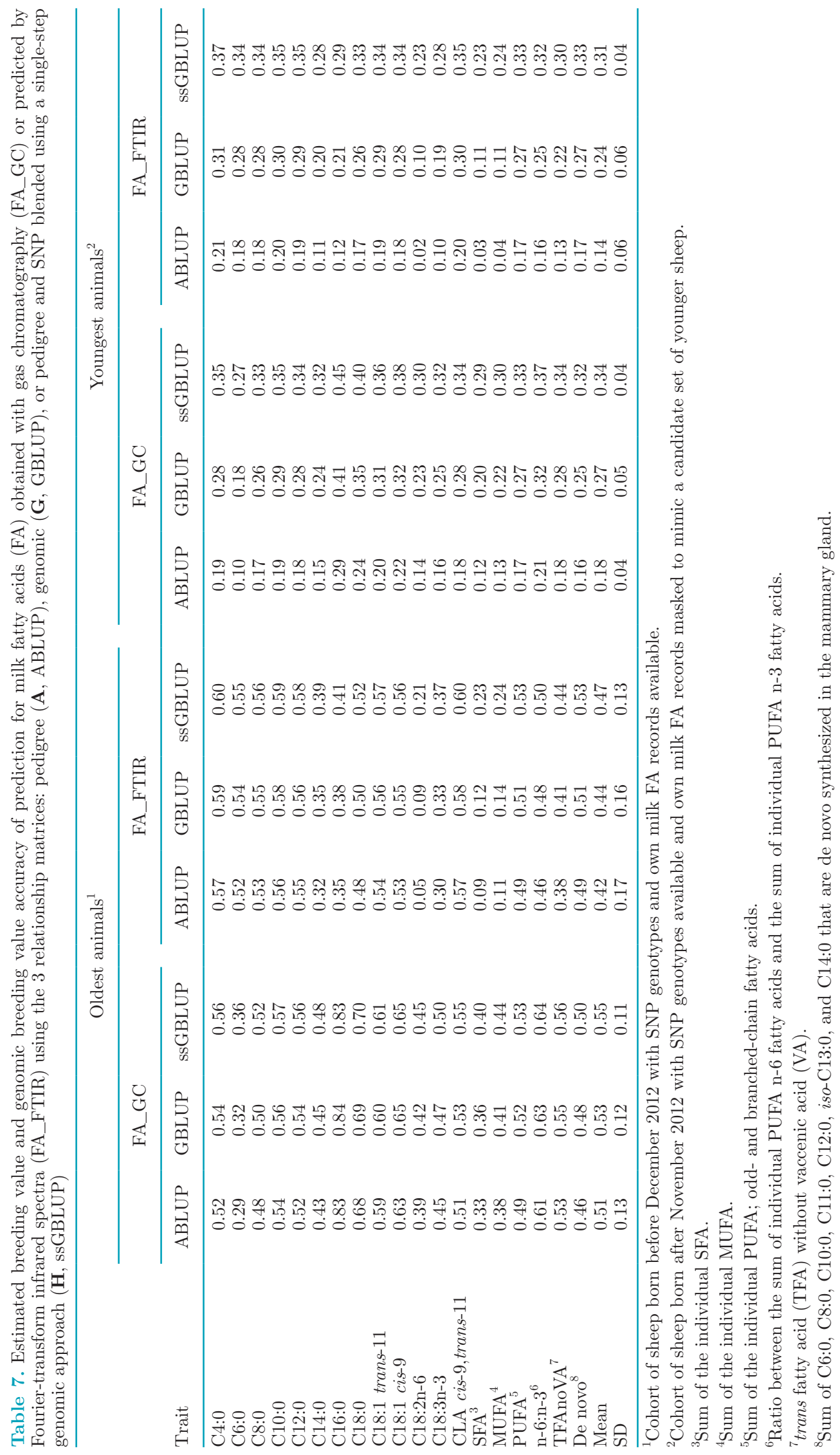


more accurately relationship among animals because the realized fraction of allele shared between individual is directly computed (Hayes et al., 2009; Legarra et al., 2014), with subsequent large $\mathrm{h}^{2}$ estimates.

\section{Accuracy of EBV and GEBV Predictions}

In our study breeding value accuracies for FA milk profile were low to moderate. Considering the sample size, the genetic architecture of milk FA composition, and the number of records per ewe our results are in accordance to GS theory (Goddard and Hayes, 2009). Animals with their own phenotypes exhibited larger accuracies compared with young animals. However, the addition of genotype information to the breeding value prediction resulted in an improvement of accuracy, also in latter group. Other studies in sheep underlined the higher accuracy of genomic methods compared with the pedigree-based approach for milk and meat production traits (Daetwyler et al., 2012; Legarra et al., 2014; Baloche et al., 2014). Moreover, GS studies carried out in beef cattle on muscle FA composition reported for some of FA also investigated in this study a similar pattern of GEBV accuracy (Chen et al., 2015; Chiaia et al., 2017; Zhu et al., 2017).

The similar magnitude of GEBV accuracy for FA_ FTIR and FA_GC is interesting for a possible implementation breeding program for milk FA composition in dairy sheep, due to the considerable reduction of phenotyping cost. The predictive ability of FTIR spectra $\left(\mathrm{R}_{\text {GC-FTIR }}^{2}\right.$, see Table 3$)$ might have affected the accuracy of genomic predictions: moderate correlations between $\mathrm{R}_{\text {GC-FTIR }}^{2}$ and $(\mathrm{G})$ EBV accuracy were observed (0.46 and 0.45 in ssGBLUP for the old and young cohort, respectively).

Regarding the prediction model, the slightly higher accuracies found using ssGBLUP could be ascribable to the blended (co)variance structure that can take benefits from the inclusion of all relatives of nongenotyped and genotypes ewes with recorded traits (Aguilar et al., 2010; Legarra et al., 2014). Finally, when the selection intensity is not so high (as in Sarda sheep), the use of GS with genotyped females may help to improve milk composition traits even of unphenotyped animals (young cohort) as already suggested in a simulation study by Gorjanc et al. (2015).

However, the complex genetic correlation pattern that exist among the different FA should be carefully taken into account (Carta et al., 2008; Sánchez et al., 2010) when implementing a coherent selection goal aimed at improving the milk FA composition. Actually, the use of a bivariate approach resulted in negligible differences of GEBV accuracies compared with the univariate models (in many cases of 0.01), and only in few cases a slight improvement (0.03-0.07) was observed. Apart from a sampling effect, other possible explanations can be found in the relevant literature. Previous studies using either simulated (Calus and Veerkamp, 2011; Guo et al., 2014) or real type trait (Tsuruta et al., 2011) data reported from zero to low advantages for multiple trait GEBV accuracy over single trait evaluations. According to these authors, superiority of multiple over single trait accuracies depends on the amount of unphenotyped animals (i.e., missing data), and on the $\mathrm{h}^{2}$ and genetic relationship among considered traits. In the present work, the number of unphenotyped animals was equal for both traits considered in the bivariate analysis, [i.e., the scenario that according to previous simulation studies (Calus and Veerkamp, 2011; Guo et al., 2014) did not result in any improvement of accuracy]. Moreover, accuracy gains here observed (Table 8) were for traits with low $h^{2}$. This result is also in agreement to what was previously reported (Jia and Jannink, 2012; Guo et al., 2014).

\section{CONCLUSIONS}

Fourier-transform infrared spectrography is commonly used in the dairy industry for milk composition recordings. The results presented in the current investigation confirmed that in dairy sheep FTIR-predicted FA are heritable traits, exhibiting low to moderate $h^{2}$. These figures are comparable to those estimated from more expensive and time-consuming GC-measured phenotypes. Moreover, breeding value accuracies obtained with GS methods were always higher than those estimated with a traditional pedigree-based approach, and ssGBLUP outperformed the GBLUP method. The use of a bivariate model resulted in a slight improvement of GEBV accuracy for only a few traits. Results of the present study, although referring to a sample of limited size, suggest that the combination of FTIR predictions and GS technology could represent an interesting option for the genetic improvement of milk FA composition in dairy sheep.

\section{ACKNOWLEDGMENTS}

This research was funded by the Regional Government (Grant no. CRP 61608 "Il latte Ovino della Sardegna") and Italian Research Project "GenHome." The authors acknowledge the Provincial Breeders Associations (AIPA) of Cagliari, Nuoro, Sassari, and Oristano (Italy); the laboratory of Sardinian Breeders Association (ARA, Oristano, Italy) for providing milk spectra; and the Italian Associations of Animal Breeders (AIA). Authors are grateful to Daniela Lourenco (University 
of Georgia, Athens) for her useful suggestions on implementing genomic models.

\section{REFERENCES}

Aguilar, I., I. Misztal, D. L. Johnson, A. Legarra, S. Tsuruta, and T. J. Lawlor. 2010. Hot topic: A unified approach to utilize phenotypic, full pedigree, and genomic information for genetic evaluation of Holstein final score. J. Dairy Sci. 93:743-752.

Arnould, V. M., and H. Soyeurt. 2009. Genetic variability of milk fatty acids. J. Appl. Genet. 50:29-39.

Astruc, J. M., F. Barillet, A. Carta, M. Fioretti, E. Gootwine, D. Kompan, F. J. Romberg, and E. Ugarte. 2008. Report of the working group on milk recording of sheep. Pages 275-282 in Proc. 36th Biennial Session of the International Committee for Animal Recording (ICAR), Niagara Falls, NY. ICAR technical series no. 13. Identification, breeding, production, health and recording on farm animals. J. D. Slatter, ed. ICAR, Rome, Italy.

Baloche, G., A. Legarra, G. Sallé, H. Larroque, J. M. Astruc, C. Robert-Granié, and F. Barillet. 2014. Assessment of accuracy of genomic prediction for French Lacaune dairy sheep. J. Dairy Sci. 97:1107-1116.

Banni, S., S. D. Heys, and K. W. J. Wahle. 2003. Conjugated linoleic acids as anticancer nutrients: Studies in vivo and cellular mechanisms. Pages 267-282 in Advances in Conjugated Linoleic Acid Research. W. W. Christie, J-L. Sébédio, and R. Adlof, ed. AOCS Press, Urbana, IL.

Bastin, C., N. Gengler, and H. Soyeurt. 2011. Phenotypic and genetic variability of production traits and milk fatty acid contents across days in milk for Walloon Holstein first parity cows. J. Dairy Sci. 94:4152-4163.

Bastin, C., H. Soyeurt, and N. Gengler. 2013. Genetic parameters of milk production traits and fatty acid contents in milk for Holstein cows in parity 1-3. J. Anim. Breed. Genet. 130:118-127.

Bhattacharya, A., J. Banu, M. Rahman, J. Causey, and G. Fernandes. 2006. Biological effects of conjugated linoleic acids in health and disease. J. Nutr. Biochem. 17:789-810.

Boichard, D., and M. Brochard. 2012. New phenotypes for new breeding goals in dairy cattle. Animal 6:544-550.

Boichard, D., A. Govignon-Gion, H. Larroque, C. Maroteau, I. Palhière, G. Tosser-Klopp, R. Rupp, M. P. Sanchez, and M. Brochard. 2014. Déterminisme génétique de la composition en acides gras et protéines du lait des ruminants, et potentialités de sélection. INRA Prod. Anim. 27:283-298.

Bonfatti, V., D. Vicario, A. Lugo, and P. Carnier. 2017. Genetic parameters of measures and population-wide infrared predictions of 92 traits describing the fine composition and technological properties of milk in Italian Simmental cattle. J. Dairy Sci. 100:55265540 .

Bouwman, A. C., H. Bovenhuis, M. H. Visker, and J. A. van Arendonk. 2011. Genome-wide association of milk fatty acids in Dutch dairy cattle. BMC Genet. 12:43.

Buitenhuis, B., L. L. Janss, N. A. Poulsen, L. B. Larsen, M. K. Larsen, and P. Sørensen. 2014. Genome-wide association and biological pathway analysis for milk-fat composition in Danish Holstein and Danish Jersey cattle. BMC Genomics 15:1112.

Cabiddu, A., M. Decandia, M. Addis, G. Piredda, A. Pirisi, and G. Molle. 2005. Managing Mediterranean pastures in order to enhance the level of beneficial fatty acids in sheep milk. Small Rumin. Res. 59:169-180.

Calus, M. P., and R. F. Veerkamp. 2011. Accuracy of multi-trait genomic selection using different methods. Genet. Sel. Evol. 43:26.

Caredda, M., M. Addis, I. Ibba, R. Leardi, M. F. Scintu, G. Piredda, and G. Sanna. 2016. Prediction of fatty acid content in sheep milk by mid-infrared spectrometry with a selection of wavelengths by genetic algorithms. Food Sci. Technol. Leb. 65:503-510.

Carta, A., S. Casu, and S. Salaris. 2009. Invited review: Current state of genetic improvement in dairy sheep. J. Dairy Sci. 92:5814-5833.

Carta, A., S. Casu, M. G. Usai, M. Addis, M. Fiori, A. Fraghì, S. Miari, L. Mura, G. Piredda, L. Schibler, T. Sechi, J. M. Elsen, and
F. Barillet. 2008. Investigating the genetic component of fatty acid content in sheep milk. Small Rumin. Res. 79:22-28.

Cecchinato, A., M. De Marchi, L. Gallo, G. Bittante, and P. Carnier. 2009. Mid-infrared spectroscopy predictions as indicator traits in breeding programs for enhanced coagulation properties of milk. J. Dairy Sci. 92:5304-5313.

Chiaia, H. L. J., E. Peripoli, R. M. de Oliveira Silva, C. Aboujaoude, F. L. B. Feitosa, M. V. A. de Lemos, M. P. Berton, B. Ferreira Olivieri, R. Espigolan, R. L. Tonussi, D. G. Mansan Gordo, T. Bresolin, A. F. Braga Magalhães, G. A. Fernandes Júnior, L. G. de Albuquerque, H. Nunes de Oliveira, J. de Jesus Mangini Furlan, A. M. Ferrinho, L. F. Mueller, H. Tonhati, A. S. Cravo Pereira, and F. Baldi. 2017. Genomic prediction for beef fatty acid profile in Nellore cattle. Meat Sci. 128:60-67.

Chen, L., C. Ekine-Dzivenu, M. Vinsky, J. Basarab, J. Aalhus, M. E. Dugan, C. Fitzsimmons, P. Stothard, and C. Li. 2015. Genomewide association and genomic prediction of breeding values for fatty acid composition in subcutaneous adipose and longissimus lumborum muscle of beef cattle. BMC Genet. 16:135.

Correddu, F., M. Cellesi, J. Serdino, M. G. Manca, M. Contu, C. Dimauro, I. Ibba, and N. P. P. Macciotta. 2018. Genetic parameters of milk fatty acid profile in sheep: Comparison between gas chromatographic measurements and Fourier-Transform Infrared Spectroscopy predictions. Animal https://doi.org/10.1017/ S1751731118001659.

Crisà, A., C. Marchitelli, L. Pariset, G. Contarini, F. Signorelli, F. Napolitano, G. Catillo, A. Valentini, and B. Moioli. 2010. Exploring polymorphisms and effects of candidate genes on milk fat quality in dairy sheep. J. Dairy Sci. 93:3834-3845.

Daetwyler, H. D., A. A. Swan, J. H. van der Werf, and B. J. Hayes. 2012. Accuracy of pedigree and genomic predictions of carcass and novel meat quality traits in multi-breed sheep data assessed by cross-validation. Genet. Sel. Evol. 44:33.

De Marchi, M., M. Penasa, A. Cecchinato, M. Mele, P. Secchiari, and G. Bittante. 2011. Effectiveness of mid-infrared spectroscopy to predict fatty acid composition of Brown Swiss bovine milk. Animal 5:1653-1658.

Dehareng, F., C. Delfosse, E. Froidmont, H. Soyeurt, C. Martin, N. Gengler, A. Vanlierde, and P. Dardenne. 2012. Potential use of milk mid-infrared spectra to predict individual methane emission of dairy cows. Animal 6:1694-1701.

Duchemin, S., H. Bovenhuis, W. M. Stoop, A. C. Bouwman, J. A. M. Van Arendonk, and M. H. P. W. Visker. 2013. Genetic correlation between composition of bovine milk fat in winter and summer, and DGAT1 and SCD1 by season interactions. J. Dairy Sci 96:592-604.

Duchemin, S. I., C. Colombani, A. Legarra, G. Baloche, H. Larroque, J. M. Astruc, F. Barillet, C. Robert-Granié, and E. Manfredi. 2012. Genomic selection in the French Lacaune dairy sheep breed. J. Dairy Sci. 95:2723-2733.

Ferrand-Calmels, M., I. Palhière, M. Brochard, O. Leray, J. M. Astruc, M. R. Aurel, S. Barbey, F. Bouvier, P. Brunschwig, H. Caillat, M. Douguet, F. Faucon-Lahalle, M. Gelé, G. Thomas, J. M. Trommenschlager, and M. Douguet. 2014. Prediction of fatty acid profiles in cow, ewe, and goat milk by mid-infrared spectrometry. J. Dairy Sci. 97:17-35

Fleming, A. 2016. Phenotypic and genetic variation of milk fat components incorporating mid-infrared technology. Doctoral Thesis, Department of Animal and Poultry Science, University of Guelph, Ontario, Canada.

Goddard, M. E., and B. J. Hayes. 2009. Mapping genes for complex traits in domestic animals and their use in breeding programmes. Nat. Rev. Genet. 10:381.

Gorjanc, G., P. Bijma, and J. M. Hickey. 2015. Reliability of pedigreebased and genomic evaluations in selected populations. Genet. Sel. Evol. 47:65.

Guo, G., F. Zhao, Y. Wang, Y. Zhang, L. Du, and G. Su. 2014. Comparison of single-trait and multiple-trait genomic prediction models. BMC Genet. 15:30.

Haile-Mariam, M., G. J. Nieuwhof, K. T. Beard, K. V. Konstatinov, and B. J. Hayes. 2013. Comparison of heritabilities of dairy traits 
in Australian Holstein-Friesian cattle from genomic and pedigree data and implications for genomic evaluations. J. Anim. Breed. Genet. 130:20-31.

Hayes, B. J., P. M. Visscher, and M. E. Goddard. 2009. Increased accuracy of artificial selection by using the realized relationship matrix. Genet. Res. (Camb.) 91:47-60.

International Sheep Genomics Consortium. 2010. The sheep genome reference sequence: A work in progress. Anim. Genet. 41:449-453.

Jia, Y., and J. L. Jannink. 2012. Multiple trait genomic selection methods increase genetic value prediction accuracy. Genetics 192:1513-1522.

Kijas, J. W., L. Porto-Neto, S. Dominik, A. Reverter, R. Bunch, R. McCulloch, B. J. Hayes, R. Brauning, J. McEwan, and the International Sheep Genomics Consortium. 2014. Linkage disequilibrium over short physical distances measured in sheep using a high-density SNP chip. Anim. Genet. 45:754-757.

Legarra, A., G. Baloche, F. Barillet, J. M. Astruc, C. Soulas, X. Aguerre, F. Arrese, L. Mintigi, M. Lasarte, F. Maeztu, I. Beltrán de Heredia, and E. Ugarte. 2014. Within-and across-breed genomic predictions and genomic relationships for Western Pyrenees dairy sheep breeds Latxa, Manech, and Basco-Béarnaise. J. Dairy Sci. 97:3200-3212.

Loberg, A., J. W. Dürr, W. F. Fikse, H. Jorjani, and L. Crooks. 2015. Estimates of genetic variance and variance of predicted genetic merits using pedigree or genomic relationship matrices in six Brown Swiss cattle populations for different traits. J. Anim. Breed. Genet. 132:376-385.

Macciotta, N. P. P., M. Mele, A. Cappio-Borlino, and P. Secchiari. 2005. Issues and perspectives in dairy sheep breeding. Ital. J. Anim. Sci. 4:5-23.

McParland, S., G. Banos, E. Wall, M. P. Coffey, H. Soyeurt, R. F. Veerkamp, and D. P. Berry. 2011. The use of mid-infrared spectrometry to predict body energy status of Holstein cows. J. Dairy Sci. 94:3651-3661.

Mele, M., G. Contarini, L. Cercaci, A. Serra, A. Buccioni, M. Povolo, G. Conte, A. Funaro, S. Banni, G. Lercker, and P. Secchiari. 2011. Enrichment of Pecorino cheese with conjugated linoleic acid by feeding dairy ewes with extruded linseed: Effect on fatty acid and triglycerides composition and on oxidative stability. Int. Dairy J. 21:365-372.

Mele, M., R. Dal Zotto, M. Cassandro, G. Conte, A. Serra, A. Buccioni, G. Bittante, and P. Secchiari. 2009. Genetic parameters for conjugated linoleic acid, selected milk fatty acids, and milk fatty acid unsaturation of Italian Holstein-Friesian cows. J. Dairy Sci. 92:392-400.

Meuwissen, T. H. E., B. J. Hayes, and M. E. Goddard. 2001. Prediction of total genetic value using genome-wide dense marker maps. Genetics 157:1819-1829.

Misztal, I., S. Tsuruta, D. Lourenco, I. Aguilar, A. Legarra, and Z. Vitezica. 2015. Manual for BLUPF90 family of programs. Accessed Jan. 20, 2018. http://nce.ads.uga.edu/wiki/lib/exe/fetch .php?media=blupf90_all2.pdf.

Moioli, B., G. Contarini, L. Pariset, C. Marchitelli, A. Crisà, G. Catillo, and F. Napolitano. 2012. Genetic variation of C18:1 and C18:2 isomers in sheep milk fat. Small Rumin. Res. 103:187-193.

Narayana, S. G., F. S. Schenkel, A. Fleming, A. Koeck, F. Malchiodi, J. Jamrozik, J. Johnston, M. Sargolzai, and F. Miglior. 2017. Genetic analysis of groups of mid-infrared predicted fatty acids in milk. J. Dairy Sci. 100:4731-4744.

Nicolazzi, E. L., A. Caprera, N. Nazzicari, P. Cozzi, F. Strozzi, C. Lawley, A. Pirani, C. Soans, F. Brew, H. Jorjani, G. Evans, B. Simpson, G. Tosser-Klopp, R. Brauning, J. L. Williams, and A. Stella. 2015. SNPchiMp v.3: Integrating and standardizing single nucleotide polymorphism data for livestock species. BMC Genomics 16:283.

Nudda, A., G. Battacone, O. Boaventura Neto, A. Cannas, A. H. D. Francesconi, A. S. Atzori, and G. Pulina. 2014. Feeding strategies to design the fatty acid profile of sheep milk and cheese. Rev. Bras. Zootec. 43:445-456.
Pegolo, S., A. Cecchinato, J. Casellas, G. Conte, M. Mele, S. Schiavon, and G. Bittante. 2016. Genetic and environmental relationships of detailed milk fatty acids profile determined by gas chromatography in Brown Swiss cows. J. Dairy Sci. 99:1315-1330.

Pegolo, S., G. Stocco, M. Mele, S. Schiavon, G. Bittante, and A. Cecchinato. 2017. Factors affecting variations in the detailed fatty acid profile of Mediterranean buffalo milk determined by 2-dimensional gas chromatography. J. Dairy Sci. 100:2564-2576.

Pulina, G., M. J. Milán, M. P. Lavín, A. Theodoridis, E. Morin, J. Capote, D. L. Thomas, A. H. D. Francesconi, and G. Caja. 2018. Invited review: Current production trends, farm structures, and economics of the dairy sheep and goat sectors. J. Dairy Sci. In press.

Purcell, S., B. Neale, K. Todd-Brown, L. Thomas, M. A. R. Ferreira, D. Bender, J. Maller, P. Sklar, P. I. W. de Bakker, M. J. Daly, and P. C. Sham. 2007. PLINK: A tool set for whole-genome association and population-based linkage analyses. Am. J. Hum. Genet. $81: 559-575$.

Rovadoscki, G. A., S. F. N. Pertile, A. B. Alvarenga, A. S. M. Cesar, F. Pértille, J. Petrini, V. Franzo, W. V. B. Soares, G. Morota, M. L. Spangler, L. F. B. Pinto, G. P. Carvalho, D. P. D. Lanna, L. L. Coutinhoand, and G. B. Mourão. 2018. Estimates of genomic heritability and genome-wide association study for fatty acids profile in Santa Inês sheep. BMC Genomics 19:375.

Rupp, R., S. Mucha, H. Larroque, J. McEwan, and J. Conington. 2016. Genomic application in sheep and goat breeding. Anim. Front. 6:39-44.

Rutten, M. J. M., H. Bovenhuis, and J. A. M. Van Arendonk. 2010. The effect of the number of observations used for Fourier transform infrared model calibration for bovine milk fat composition on the estimated genetic parameters of the predicted data. J. Dairy Sci. 93:4872-4882.

Sánchez, J. P., F. San Primitivo, E. Barbosa, L. Varona, and L. F. De La Fuente. 2010. Genetic determination of fatty acid composition in Spanish Churra sheep milk. J. Dairy Sci. 93:330-339.

Soyeurt, H., A. Gillon, S. Vanderick, P. Mayeres, C. Bertozzi, and N. Gengler. 2007. Estimation of heritability and genetic correlations for the major fatty acids in bovine milk. J. Dairy Sci. 90:44354442 .

Stoop, W. M., A. Schennink, M. H. Visker, E. Mullaart, J. A. van Arendonk, and H. Bovenhuis. 2009. Genome-wide scan for bovine milk-fat composition. I. Quantitative trait loci for short-and medium-chain fatty acids. J. Dairy Sci. 92:4664-4675.

Stoop, W. M., J. A. M. van Arendonk, J. M. L. Heck, H. J. F. van Valenberg, and H. Bovenhuis. 2008. Genetic parameters for major milk fatty acids and milk production traits of Dutch HolsteinFriesians. J. Dairy Sci. 91:385-394.

Tsuruta, S., I. Misztal, I. Aguilar, and T. J. Lawlor. 2011. Multipletrait genomic evaluation of linear type traits using genomic and phenotypic data in US Holsteins. J. Dairy Sci. 94:4198-4204.

Tsuruta, S., I. Misztal, and T. J. Lawlor. 2013. Genomic evaluations of final score for US Holsteins benefit from the inclusion of genotypes on cows. J. Dairy Sci. 96:3332-3335.

Uemoto, Y., T. Abe, N. Tameoka, H. Hasebe, K. Inoue, H. Nakajima, N. Shoji, M. Kobayashi, and E. Kobayashi. 2011. Whole-genome association study for fatty acid composition of oleic acid in Japanese Black cattle. Anim. Genet. 42:141-148.

VanRaden, P. M. 2008. Efficient methods to compute genomic predictions. J. Dairy Sci. 91:4414-4423.

Veerkamp, R. F., H. A. Mulder, R. Thompson, and M. P. L. Calus. 2011. Genomic and pedigree-based genetic parameters for scarcely recorded traits when some animals are genotyped. J. Dairy Sci. 94:4189-4197.

Zhu, B., H. Niu, W. Zhang, Z. Wang, Y. Liang, L. Guan, P. Guo, Y. Chen, L. Zhang, Y. Guo, H. Ni, X. Gao, L. Xu, and J. Li. 2017. Genome wide association study and genomic prediction for fatty acid composition in Chinese Simmental beef cattle using high density SNP array. BMC Genomics 18:464. 


\section{APPENDIX}

Table A1. Single fatty acid (FA) used to define groups of FA analyzed

Group of FA

SFA: sum of individual SFA

MUFA: sum of individual MUFA

PUFA: sum of individual PUFA

TFAnoVA

PUFA n-6:PUFA n-3

De novo: de novo synthesized in the mammary gland

\section{Single FA}

C4:0, C6:0, C0, C8:0, C9:0, C10:0, C11:0, C12:0, iso-C13:0, anteiso-C13:0, iso-C14:0, C14:0, iso-C15:0, anteiso-C15:0, C15:0, iso-C16:0, C16:0, iso-C17:0, anteiso-C17:0, C17:0, iso-C18:0, C18:0, C19:0, C20:0, C22:0, C23:0, C24:0, C25:0, C26:0

C10:1. C14:1 cis-9, C15:1, C16:1 trans-4, C16:1 trans-5, C16:1 trans-6+trans-7, C16:1 trans-9, C16:1 trans-10, C16:1 trans-11+trans-12, C16:1 cis-7, C16:1 cis-9, C16:1 cis-10, C16:1 cis-11, C17:1 cis6+cis-7, C17:1 cis-8, C17:1 cis-9, C18:1 trans-4, C18:1 trans-5, C18:1 trans-6+trans-8, C18:1 trans-9, C18:1 trans-10, C18:1 trans-11, C18:1 trans-12, C18:1 trans-13+trans-14, C18:1 cis-9, C18:1 trans15+cis-10, C18:1 cis-11, C18:1 cis-12, C18:1 cis-13, C18:1 trans-16+cis-14, C18:1 cis-15, C18:1 cis-16, C20:1 cis-5, C20:1 cis-9, C20:1 cis-11, C20:1 cis-15, C22:1n-9, C24:1 cis-15

C18:2 trans-10,trans-14, C18:2 trans-11,trans-15, C18:2 trans-9,trans-12, C18:2 cis-9,trans-13, C18:2 trans-8,cis-13, C18:2 cis-9,trans-12, C18:2 trans-9,cis-12, C18:2 trans-11,cis-15, C18:2n-6, C18:2 trans12,cis-15, C18:2 cis-12,cis-15, CLA cis-9,trans-11, CLA trans-9, cis-11, CLA trans-10,cis-12, CLA trans11,cis-13, CLA trans-12,trans-14, CLA trans-11,trans-13, CLA trans-9,trans-11, C20:2n-9, C20:2n-6, C22:2n-6, C18:3n-6, C18:3n-3, C20:3n-9, C20:3n-6, C20:3, C20:3n-3, C22:3n-6, C18:4n-3, C20:4n-6, $\mathrm{C} 20: 4 \mathrm{n}-3, \mathrm{C} 22: 4 \mathrm{n}-6, \mathrm{C} 20: 5 \mathrm{n}-3, \mathrm{C} 22: 5 \mathrm{n}-3, \mathrm{C} 22: 6 \mathrm{n}-3$

Sum of individual trans FA excluding C18:1 trans-11 (vaccenic acid)

Ratio between the sum of individual PUFA n- 6 and the sum of all individual PUFA n-3 C6:0, C8:0, C10:0, C11:0, C12:0, iso-C13:0, and C14:0 
GENOMIC SELECTION FOR SHEEP MILK FATTY ACIDS

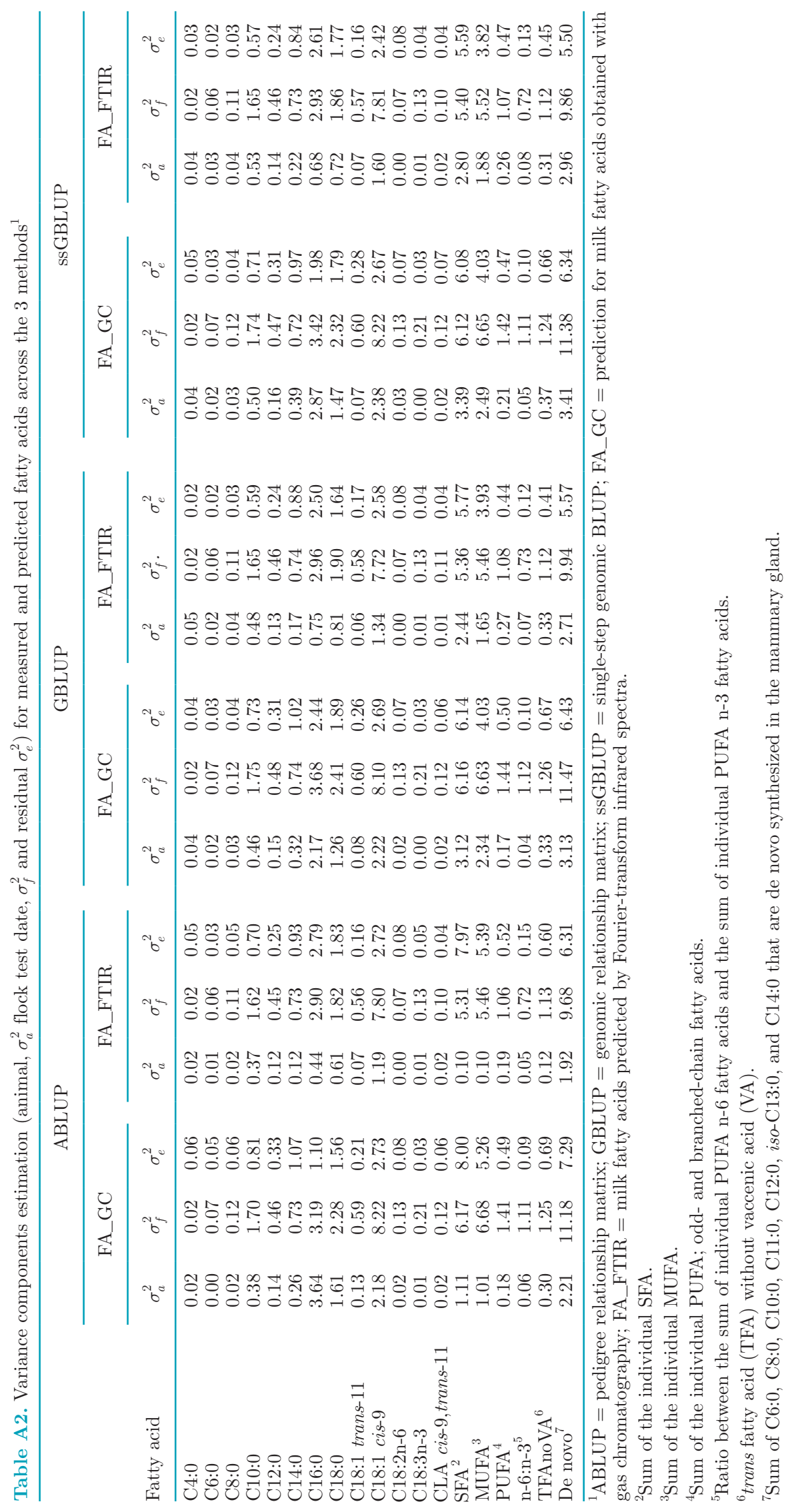

Journal of Dairy Science Vol. 102 No. 4, 2019 